\title{
Acetone-butanol-ethanol production from corn stover pretreated by alkaline twin-screw extrusion pretreatment
}

\author{
Yuedong Zhang $\cdot$ Tongang Hou $\cdot$ Bin Li $\cdot$ \\ Chao Liu $\cdot$ Xindong Mu $\cdot$ Haisong Wang
}

Received: 23 May 2013/Accepted: 9 September 2013/Published online: 10 October 2013

(c) Springer-Verlag Berlin Heidelberg 2013

\begin{abstract}
In this study, the alkaline twin-screw extrusion pretreated corn stover was subjected to enzymatic hydrolysis after washing. The impact of solid loading and enzyme dose on enzymatic hydrolysis was investigated. It was found that $68.2 \mathrm{~g} / \mathrm{L}$ of total fermentable sugar could be obtained after enzymatic hydrolysis with the solid loading of $10 \%$, while the highest sugar recovery of $91.07 \%$ was achieved when the solid loading was $2 \%$ with the cellulase dose of $24 \mathrm{FPU} / \mathrm{g}$ substrate. Subsequently, the hydrolyzate was fermented by Clostridium acetobutylicum ATCC 824 . The acetone-butanol-ethanol (ABE) production of the hydrolyzate was compared with the glucose, xylose and simulated hydrolyzate medium which have the same reducing sugar concentration. It was shown that $7.1 \mathrm{~g} / \mathrm{L}$ butanol and $11.2 \mathrm{~g} / \mathrm{L}$ ABE could be produced after $72 \mathrm{~h}$ fermentation for the hydrolyzate obtained from enzymatic hydrolysis with $6 \%$ solid loading. This is comparable to the glucose and simulated hydrozate medium, and the overall $\mathrm{ABE}$ yield could reach $0.112 \mathrm{~g} / \mathrm{g}$ raw corn stover.
\end{abstract}

Keywords Alkaline twin-screw extrusion pretreatment $\cdot$ Enzymatic saccharification - Acetonebutanol-ethanol (ABE) · Corn stover · Clostridium acetobutylicum ATCC 824 . Fermentation

\footnotetext{
Y. Zhang $\cdot$ T. Hou $\cdot$ B. Li $\cdot$ C. Liu $\cdot$ X. Mu $(\bowtie) \cdot$

H. Wang $(\bowtie)$

Key Laboratory of Biofuel, Qingdao Institute of Bioenergy and Bioprocess Technology, Chinese Academy of Sciences, Qingdao 266101, Shandong, China

e-mail: muxd@qibebt.ac.cn

H. Wang

e-mail: wanghs@qibebt.ac.cn

Y. Zhang

e-mail: zhangyd@qibebt.ac.cn
}

\section{Introduction}

Recently, great efforts have been dedicated to the secondgeneration biofuel research to make a more sustainable substitute for fossil-based energy. A variety of renewable resources, such as corn stover [1,2], wheat straw [3] and wood [4], have been employed for the production of ethanol or butanol. Corn stover, which is an abundant and easilycollected agricultural waste, needs to be pretreated and enzymatically hydrolyzed into monosaccharides for the further use of microbes, as the microbes cannot efficiently and directly convert lignocellulosic biomass to ethanol or butanol due to its natural recalcitrance. A lot of methods for the preparation of fermentation culture from lignocellulosic biomass were reported, but the issues, such as the use of corrosive chemicals, potential environmental pollution, generation of inhibitory compounds, and high capital or operational costs limit their large-scale utilizations.

Extrusion pretreatment is a relatively novel physicochemical method in which biomass is processed by means of heat, compression and shear forces, leading to physical disruption and chemical modifications of biomass during the passage through the extruder [5-9]. In our previous studies $[10,11]$, a novel pilot-scale alkaline twin-screw extrusion (ATSE) pretreatment process using the specially designed twin-extruder to pretreat corn stover was established. It was found that under relatively mild conditions $(\mathrm{NaOH}$ loading of $0.06 \mathrm{~g} / \mathrm{g}$ biomass, biomass/liquid ratio of $1 / 2$ (w/w), temperature of $99^{\circ} \mathrm{C}$, and $1 \mathrm{~h}$ heat preservation after extrusion), the ATSE pretreatment could effectively disrupt the lignin-carbohydrate complex and significantly improve the enzymatic digestibility of corn stover [11]. Compared with traditional pretreatment approaches like dilute acid/ alkali pretreatment, steam explosion pretreatment (i.e., AFEX or ARP), the ATSE pretreatment exhibits several 
desirable characteristics: high sugar yield (about $80 \%$ ), no need of severe size-reduction prior to the extrusion, less water usage during extrusion, relatively low temperature (about $99^{\circ} \mathrm{C}$ ) and no extra heating needed [9-11].

Although pretreatment could improve the digestibility of biomass, some compounds (e.g.,, phenolic compounds, furfural, etc.) which are toxic to ABE fermentation can be generated during pretreatment process. Among the known inhibitory compounds, the phenolic compounds generated from lignin such as ferulic and coumaric acid derivatives have been proved to be stronger inhibitors than weak acids and furan derivatives $[12,13]$. Therefore, several detoxification methods, including over-liming [14], peroxidase [15], activated charcoal and alkaline peroxide treatment [2], were applied to remove the inhibitory compounds. However, it has been recently reported that some soluble lignin compounds (SLC) could be released during enzymatic hydrolysis [2], and there is an improvement on $\mathrm{ABE}$ yield when the SLC is between 0.44 and $3.32 \mathrm{~g} / \mathrm{L}$, even though the fermentation was inhibited when SLC exceeded $1.77 \mathrm{~g} / \mathrm{L}$ [2]. The improvement is associated with the unidentified compounds in SLC (released in enzymatic hydrolysis) [2], which are different from the phenolic compounds generated during pretreatment. Thus, controlling SLC of hydrolyzate in enzymatic hydrolysis is of great importance for the downstream production of ABE.

In this study, the ATSE pretreated corn stover was subjected to enzymatic hydrolysis after washing, and enzymatic hydrolysis of ATSE pretreated corn stover was optimized. In addition, the inhibitory compounds of the hydrolyzate and the subsequent acetone-butanol-ethanol (ABE) fermentation by Clostridium acetobutylicum ATCC 824 were investigated.

\section{Materials and methods}

\section{Materials}

Corn stover was harvested from Qingdao in Shandong Province (China) in October, 2011. Before pretreatment, the corn stover was cut into 2- to 5-cm pieces in length. The enzyme cocktail was obtained from KDN Biotech Co. Ltd. The activities of cellulase, xylanase and $\beta$-glucosidase were $60 \mathrm{FPU}$ (filter paper unit)/mL, $760 \mathrm{IU}$ (international unit) $/ \mathrm{mL}$ and $30 \mathrm{IU} / \mathrm{mL}$, respectively. Other chemicals (analytical grade) were bought from Sinopharm Chemical Reagent Co. Ltd. and used as received.

\section{Pretreatment}

The corn stover was pretreated by a pilot-scale ATSE machine manufactured by Tianzheng Co. (China) with a capacity of $200 \mathrm{~kg}$ oven dry (o.d.) corn stover per hour [10, 11]. A $\mathrm{NaOH}$ solution and the biomass/liquid ratio of $1: 2$ were used in the ATES pretreatment. The $\mathrm{NaOH}$ dosage was 8 wt. \% based on the weight of corn stover (o.d.). The corn stover entered the extruder via a feed inlet continuously and was crushed by the twin-screw extruder. The screw speed was fixed at $325 \mathrm{rpm}$. Out of the ATSE machine, the samples were preserved in a thermal insulation tank for $1 \mathrm{~h}$ at about $99^{\circ} \mathrm{C}$.

The mechanism of ATSE pretreatment was discussed in our previous work [11]. In brief, the ATSE pretreatment is based on the use of a co-rotating twin-screw extruder as main treatment device. Figure 1 [11] shows the picture of the twin-screw and the basic operating principle of twinscrew extruder. The twin-screw extruder consists of two co-rotating intermeshing screws inside. Each screw consists of four transport screw elements (TSE) and four reversed screw elements (RSE). The biomass enters the main body of extruder via a feed inlet and then is pushed to the RSE by the action of TSE. RSE is the main screw element with threads whose pitch is opposite to the TSE. This results in accumulation and compression of the biomass fiber in the space between TSE and RSE as shown in Fig. 1. After crushed by transport force and the reversed force, generated by TSE and RSE respectively, the biomass is forced to pass through the skewed slots of the RSE. Then, the biomass enters the next section of TSE and RSE to be further squeezed and crushed. As repeated in this way, the biomass continuously passes through the twinscrew and thus is mechanically crushed. During the extrusion process, great mechanical forces (frictional force and shearing force) are generated among the biomass fibers and the screws. The high mechanical forces cause fibrillation and shortening of biomass fibers. In addition, during the extrusion process in ATSE machine, tremendous mechanical forces lead to the generation of a great amount of heat thereby significantly increasing the temperature (up to about $99^{\circ} \mathrm{C}$ ) of biomass. Therefore, without additional heat, the pumped alkali can be thoroughly mixed and reacted with the crushed biomass under proper conditions.

SEM results demonstrated the surface structure changes of corn stover before and after ATSE pretreatment (previously reported) [11]. After the ATSE pretreatment, the integrated structure of corn stover was broken into separated fibers and fiber bundles, and the fiber surface became coarse with fiber delamination. This kind of mechanical size reduction increases external/internal specific surface area, which benefits the enzymatic saccharification of biomass [5].

Washing process

The pretreated corn stover was washed with tap water four times through a 300-mesh nylon cloth until neutrality. For 
B

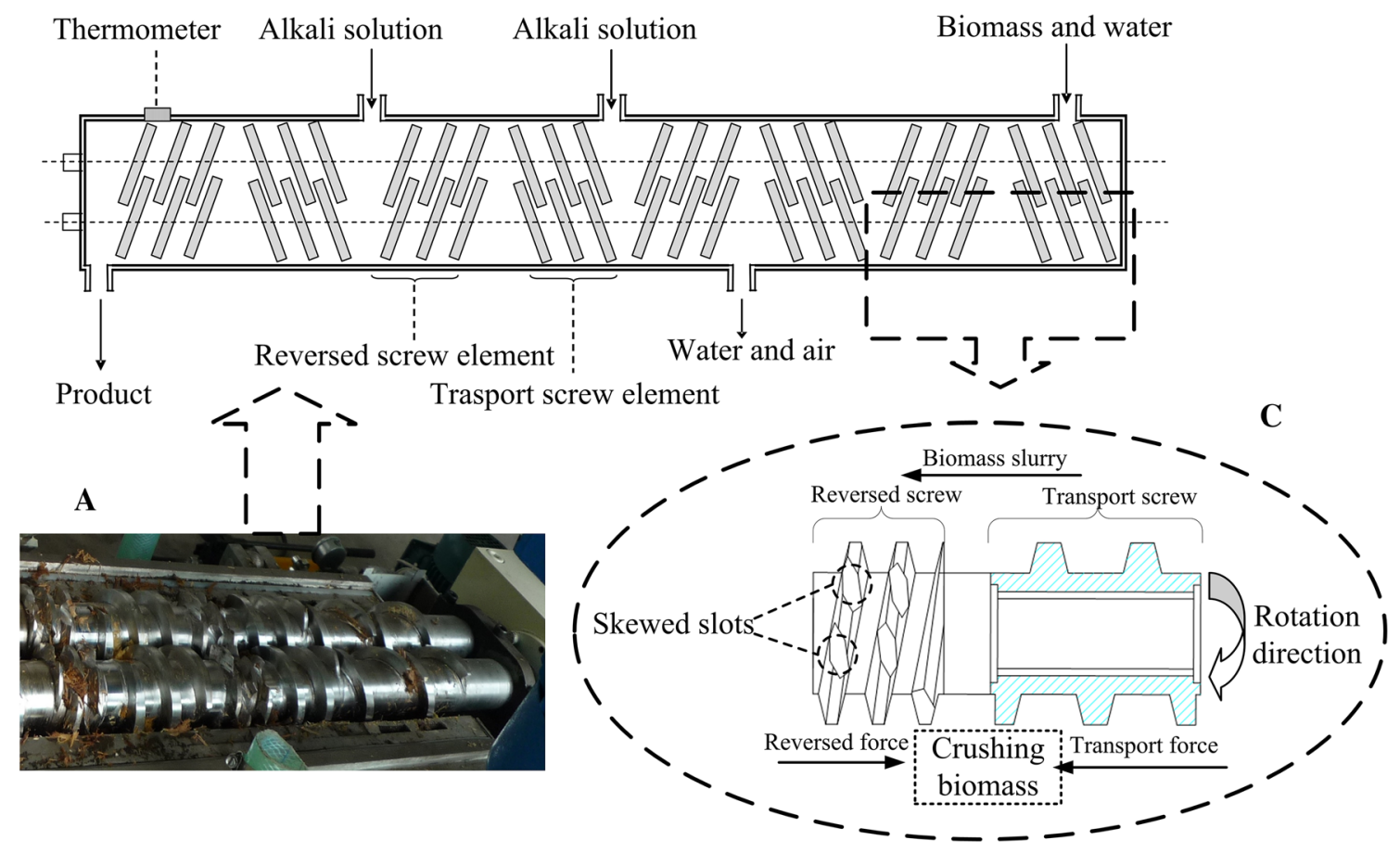

Fig. 1 The picture of specially designed twin-screw extruder and the basic operating principle of twin-screw extruder. a The picture of the specially designed twin-screw extruder, $\mathbf{b}$ the schematic diagram of

the specially designed twin-screw extruder, $\mathbf{c}$ the sketch map of a pair of reversed screw element (RSE) and transport screw element (TSE)

each time, the ratio of washing water to the pretreated corn stover was 3:1 (w/w). The washed stock was then filtered through double-layered muslin cloth with the meshes of 300 and the solid residue was collected for enzymatic hydrolysis [16].

Enzymatic hydrolysis of the ATSE pretreated corn stover

For solid loading and enzyme dose tests, a mixture $(20 \mathrm{~mL})$ of pretreated corn stover (with varied solid loading from 2 to $10 \%)$ and sodium citrate buffer $(0.1 \mathrm{M}, \mathrm{pH} 4.8)$ was added in a 50-mL capped bottle. The solid loading for enzymatic hydrolysis tests is expressed as the weight of pretreated corn stover (o.d.) divided by the total weight of materials used (pretreated corn stover, enzymes and buffer) for hydrolysis. Enzyme cocktail was added in the bottle and the enzymatic hydrolysis was carried out in $50{ }^{\circ} \mathrm{C}$ with the agitation of $160 \mathrm{rpm}$ for $48 \mathrm{~h}$. Upon completion, the hydrolyzate was filtered to remove the sediment [17], and stored at $4{ }^{\circ} \mathrm{C}$ for the composition analyses and fermentation. Sugar recovery was defined as the percentage of total sugar in hydrolyzate divided by the total sugar in pretreated corn stover. For fermentation test, the enzymatic hydrolysis was carried out in a 1-L flask with $500 \mathrm{~mL}$ mixture under the optimized conditions.
Fermentation

Studies of solvent-producing fermentation were performed in $250 \mathrm{~mL}$ screw-capped bottles containing $100 \mathrm{~mL}$ medium. Nitrogen purging at the flow rate of $100 \mathrm{~mL} / \mathrm{min}$ was conducted to generate anaerobic conditions for the fermentation. Before adding yeast extract and P2 stock [18] aseptically by filtration sterilization, all the hydrolyzate, simulate hydrolyzate and sugar medium were sterilized at $115^{\circ} \mathrm{C}$ for $30 \mathrm{~min}$, and all fermentation experiments were conducted at $37{ }^{\circ} \mathrm{C}$ with $90 \mathrm{rpm}$ of stirring for $72 \mathrm{~h}$.

Spores of Clostridium acetobutylicum ATCC 824 were maintained in distilled water at $4{ }^{\circ} \mathrm{C}$. Before use, the spores $(0.1 \mathrm{~mL})$ were heat shocked at $75^{\circ} \mathrm{C}$ for $2 \mathrm{~min}$ and transferred to reinforced clostridial media (RCM, Oxoid CM 149) for spore germination. The spores were rejuvenated anaerobically for $12 \mathrm{~h}$, and then subcultured to a P2 medium containing $30 \mathrm{~g} / \mathrm{L}$ glucose and incubated for another $6 \mathrm{~h}$. Subsequently, the P2 medium was subcultured to the solvent-producing medium at a $5 \%$ inoculation amount. The initial $\mathrm{pH}$ value of the subcultured medium was 5.5-5.7, and the final $\mathrm{pH}$ after fermentation was about 5.0 (the $\mathrm{pH}$ value was not controlled during fermentation). Samples taken from the bottles were centrifuged at $12,000 \mathrm{rpm}$ for $2 \mathrm{~min}$, and the supernatants were used for ABE fermentation and sugar analyses. All experiments 
Table 1 Characterization of feedstock and pretreated corn stover

\begin{tabular}{|c|c|c|c|c|c|c|c|c|c|}
\hline & \multirow{2}{*}{$\begin{array}{l}\text { Dry } \\
\text { weight } \\
\text { (tone) }\end{array}$} & \multicolumn{8}{|c|}{ Component $^{\mathrm{a}}(\%)$} \\
\hline & & Glucan & Xylan & Arabinan & Acetyl & $\begin{array}{l}\text { Acid } \\
\text { soluble } \\
\text { lignin }\end{array}$ & $\begin{array}{l}\text { Acid } \\
\text { insoluble } \\
\text { lignin }\end{array}$ & Extractive & Ash \\
\hline $\begin{array}{l}\text { Component } \\
\text { content of } \\
\text { raw corn } \\
\text { stover }^{\mathrm{a}}\end{array}$ & $0.450^{\mathrm{b}}$ & $32.31 \pm 0.23$ & $16.78 \pm 0.14$ & $1.94 \pm 0.06$ & $2.98 \pm 0.08$ & $1.05 \pm 0.09$ & $21.98 \pm 1.25$ & $18.45 \pm 0.76$ & $7.44 \pm 0.20$ \\
\hline $\begin{array}{l}\text { Component } \\
\text { content of } \\
\text { pretreated }^{\text {stover }}\end{array}$ & $0.268^{\mathrm{c}}$ & $53.87 \pm 0.65$ & $20.19 \pm 0.25$ & $1.29 \pm 0.10$ & $0.36 \pm 0.02$ & $0.45 \pm 0.05$ & $8.55 \pm 0.78$ & - & - \\
\hline $\begin{array}{l}\text { Recovery } \\
\text { rate }(\%)^{\mathrm{d}}\end{array}$ & & 99.3 & 72.2 & 39.6 & 12.1 & 25.5 & 23.2 & & \\
\hline \multicolumn{10}{|c|}{ a Oven dry weight basis } \\
\hline \multicolumn{10}{|c|}{ b Moisture content of raw corn stover: $10.75 \%$} \\
\hline \multicolumn{10}{|c|}{${ }^{\mathrm{c}}$ Moisture content of pretreated corn stover after washing: $76.94 \%$} \\
\hline \multicolumn{10}{|c|}{${ }^{\mathrm{d}}$ Recovery rate $(\%)=\frac{\text { dry weight of pretreated stover } \times \text { component content of pretreated stover }}{\text { dry weight of raw stover } \times \text { component content of raw stover }} \times 100$} \\
\hline
\end{tabular}

were carried out at least twice to ensure reproducibility and the average was reported.

Analytical methods

All biomass composition analyses were conducted in triplicate following NREL analytical procedure [19]. The analyses of ABE, sugar and acid content in fermentation broth were conducted as mentioned in our previous work $[10,11]$. SLC were identified by ultraviolet spectrophotometry and the SLC concentration was calculated according to the following equation [20]:

$C_{\mathrm{SLC}}=4.187 \times 10^{-2}\left(A_{280}-3.19 \times U\right)$

where $\mathrm{C}_{\mathrm{SLC}}$ is the SLC concentration $(\mathrm{g} / \mathrm{L}) ; \mathrm{A}_{280}$ is the absorbance reading at $280 \mathrm{~nm}$ after the correction for dilution; $U$ is the enzymatic activity of the sample (FPU/ $\mathrm{mL}$ ). In the equation, the interface from enzyme absorbance has been removed. The sodium citrate buffer was used as a blank test. The 3,5-dinitrosalicyclic acid method was used for quick analysis of total reducing sugar.

\section{Results and discussion}

Characterization of corn stover before and after ATSE pretreatment

The component analyses of feedstock and pretreated corn stover are shown in Table 1. It is seen that, after ATSE pretreatment, the content of glucan and xylan increased from 32.31 and $16.78 \%$ (raw material) to 53.87 and $20.19 \%$, respectively, and $99.3 \%$ of the glucan and

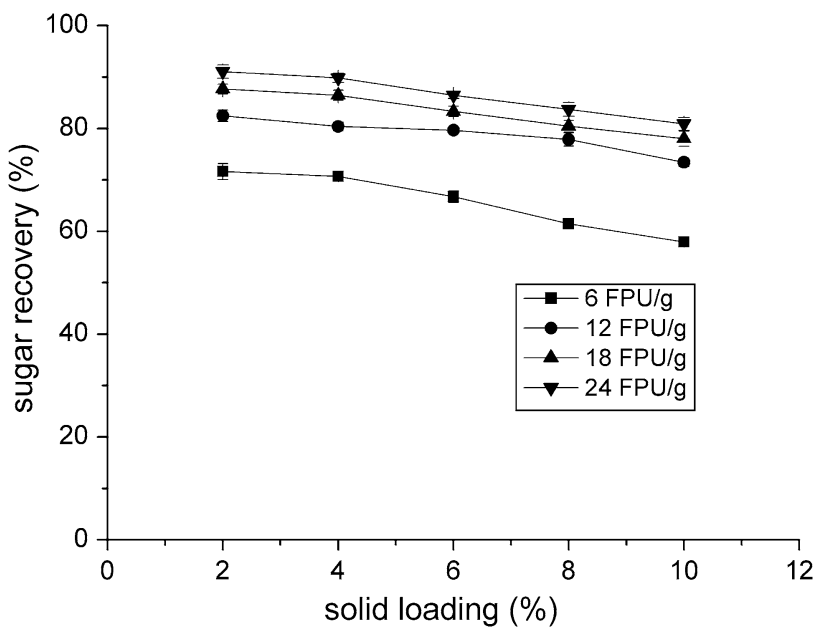

Fig. 2 The impact of solid loading of enzymatic hydrolysis on sugar recovery in different enzyme dose

$72.2 \%$ of xylan were preserved. Table 1 also presents that the content of acid insoluble lignin decreased from 21.98 to $8.55 \%$. The significant lignin removal $(77 \%)$ is mainly due to the severe disruption of corn stover during physical extrusion $[10,11]$, thus leading to a better chemical modification of biomass via facilitated the penetration of $\mathrm{NaOH}$ and delignification reactions [9].

Enzymatic hydrolysis of ATSE pretreated corn stover

Figures 2 and 3 present the impact of solid loading and cellulase dose of enzymatic hydrolysis on sugar recovery and sugar concentration, respectively. As shown in Fig. 3, the highest sugar concentration of $68.17 \mathrm{~g} / \mathrm{L}$ was achieved at $10 \%$ solid loading with the cellulase dose of $24 \mathrm{FPU} / \mathrm{g}$, 


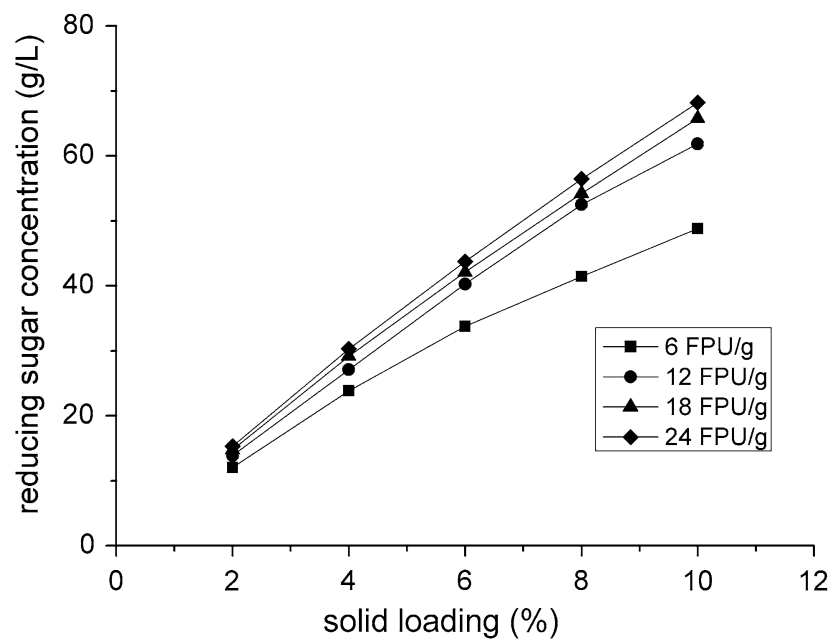

Fig. 3 The impact of solid loading of enzymatic hydrolysis on reducing sugar concentration in different enzyme doses

and the corresponding sugar recovery was $80.9 \%$ (Fig. 2). However, the highest sugar recovery of $91.07 \%$ (Fig. 2) was achieved at the $2 \%$ solid loading with the cellulase dose of $24 \mathrm{FPU} / \mathrm{g}$. Figure 2 also exhibited that the sugar recovery was significantly affected by enzyme dose. For the case of $2 \%$ solid loading, when cellulase dose increased from 6 to $12 \mathrm{FPU} / \mathrm{g}$, the sugar recovery improved about $11 \%$, while when cellulase dose elevated from 18 to $24 \mathrm{FPU} / \mathrm{g}$, the sugar recovery just increased about $3 \%$. Similar trends can also be found for high solid loading hydrolysis. This is mainly due to the difficult mass transition (enzyme penetration), because a high sugar recovery could be achieved with a high solid loading for enzymatic hydrolysis, as long as the mass transition is good enough [21]. In addition, as the ATSE pretreatment was alkali combined, some of the known microbial inhibitors produced in the acid pretreatment [e.g.,, furfural, hydroxymethyl furfural (HMF)] were not detected in spent liquor of washing. However, after $48 \mathrm{~h}$ hydrolysis, $11.6-12.3 \%$ of lignin was dissolved in the hydrolyzate (Fig. 4). This indicates that SLC could be generated during the enzymatic hydrolysis of lignocelluloses, which was also reported by Wang et al. [2] and Alvira et al. [22]. The SLC could be some small molecular lignin which generated during the alkali pretreatment. This small part of lignin re-deposited to the hemicellulose or cellulose after pretreatment [25] and was not removed in washing process. During enzymatic hydrolysis of pretreated corn stover, the re-deposited small molecular lignin was released when the hemicellulose and cellulose were hydrolyzed by enzymes, and thus dissolved in the hydrolyzate. Furthermore, the enzyme cocktail was made of the crude enzymes which were produced by lignocellulose-degrading microbes, and it contains a little laccase which could degrade some lignin

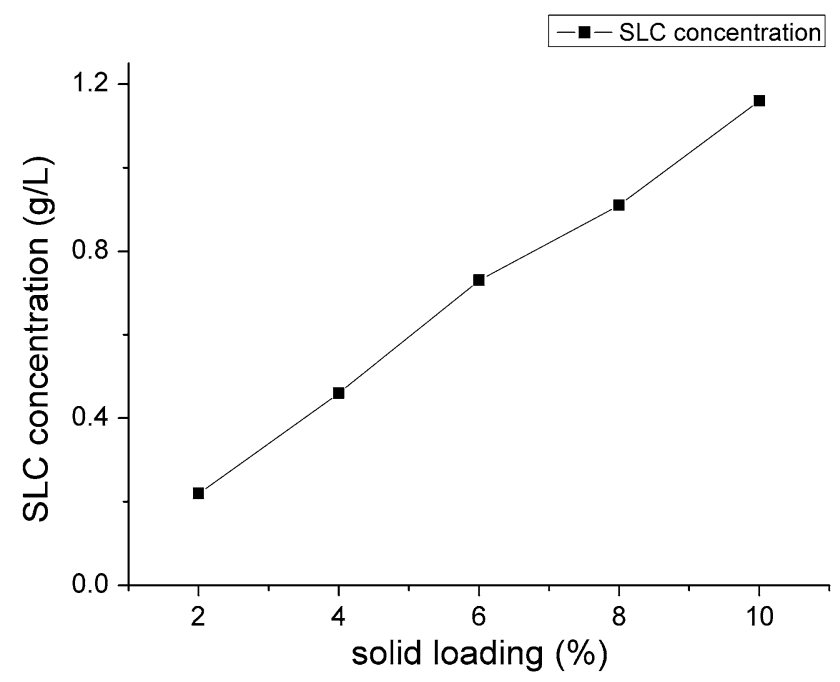

Fig. 4 SLC in the hydrolyzate of different solid loading Lignin content is $9.00 \%(\mathrm{w} / \mathrm{w})$ in the pretreated corn stover. The enzyme dosage was $18 \mathrm{FPU} / \mathrm{g}$ substrate

remained in substrate after pretreatment and washing, thus releasing a little SLC during enzymatic hydrolysis. For higher sugar utilization, no additional detoxification which could cause sugar loss was applied to the hydrolyzate. Because the fermentation could be improved when SLC is below $0.89 \mathrm{~g} / \mathrm{L}$ [2], the hydrolyzate obtained via enzymatic hydrolysis with $6 \%$ solid loading was used for the fermentation study, and the corresponding SLC was $0.74 \mathrm{~g} / \mathrm{L}$ in $500-\mathrm{mL}$ scale.

\section{$\mathrm{ABE}$ fermentation}

ATCC 824 was one of the most studied solvent-producing bacteria [2, 23, 24], and it can be used to ferment glucose, xylose, arabinose and cellobiose. The highest ABE concentration produced by ATCC 824 was $18.7 \mathrm{~g} / \mathrm{L}$ in a $60-\mathrm{g} /$ $\mathrm{L}$ glucose P2 medium, as reported in previous research [23]. To investigate the hydrolyzate sugar utility by ATCC 824 , three comparative experiments were carried out using a simulated hydrolyzate medium which has a similar mixed sugar concentration to the actual hydrolyzate, a glucose medium and a xylose medium which have a similar total sugar concentration to the actual hydrolyzate. The contents of the four mediums can be seen in Table 2. The concentrations of glucose, xylose and arabinose during ABE fermentation are shown in Fig. 5. ATCC 824 utilized the xylose like glucose when there was no glucose in the culture, as presented in Figs. 4d and 5c. The glucose was utilized faster than xylose in hydrolyzate and mixed sugar medium and exhausted first in the two mediums. At the end of fermentation, there were $0.5 \mathrm{~g} / \mathrm{L}$ total sugars left in the simulated hydrolyzate medium (Fig. $5 \mathrm{~b}$ ) and $3.1 \mathrm{~g} / \mathrm{L}$ total sugars left in the hydrolyzate (Fig. 5a). The ABE 
Table 2 Contents of solvent-producing mediums

\begin{tabular}{|c|c|c|c|c|c|c|c|}
\hline & $\begin{array}{l}\text { Cellobiose } \\
(\mathrm{g} / \mathrm{L})\end{array}$ & $\begin{array}{l}\text { Glucose } \\
(\mathrm{g} / \mathrm{L})\end{array}$ & $\begin{array}{l}\text { Xylose } \\
(\mathrm{g} / \mathrm{L})\end{array}$ & $\begin{array}{l}\text { Arabinose } \\
(\mathrm{g} / \mathrm{L})\end{array}$ & $\begin{array}{l}\text { Total sugar } \\
(\mathrm{g} / \mathrm{L})\end{array}$ & $\begin{array}{l}\text { P2 stock } \\
\%(\mathrm{v} / \mathrm{v})\end{array}$ & $\begin{array}{l}\text { Yeast extract } \\
(\mathrm{g} / \mathrm{L})\end{array}$ \\
\hline Hydrolyzate & 2.7 & 26.7 & 11.6 & 0.8 & 42.4 & 1 & 1 \\
\hline Simulated hydrolyzate medium & 2.7 & 26.7 & 11.6 & 0.8 & 42.4 & 1 & 1 \\
\hline Glucose medium & & 42.4 & - & - & 42.4 & 1 & 1 \\
\hline Xylose medium & & - & 42.4 & - & 42.4 & 1 & 1 \\
\hline
\end{tabular}
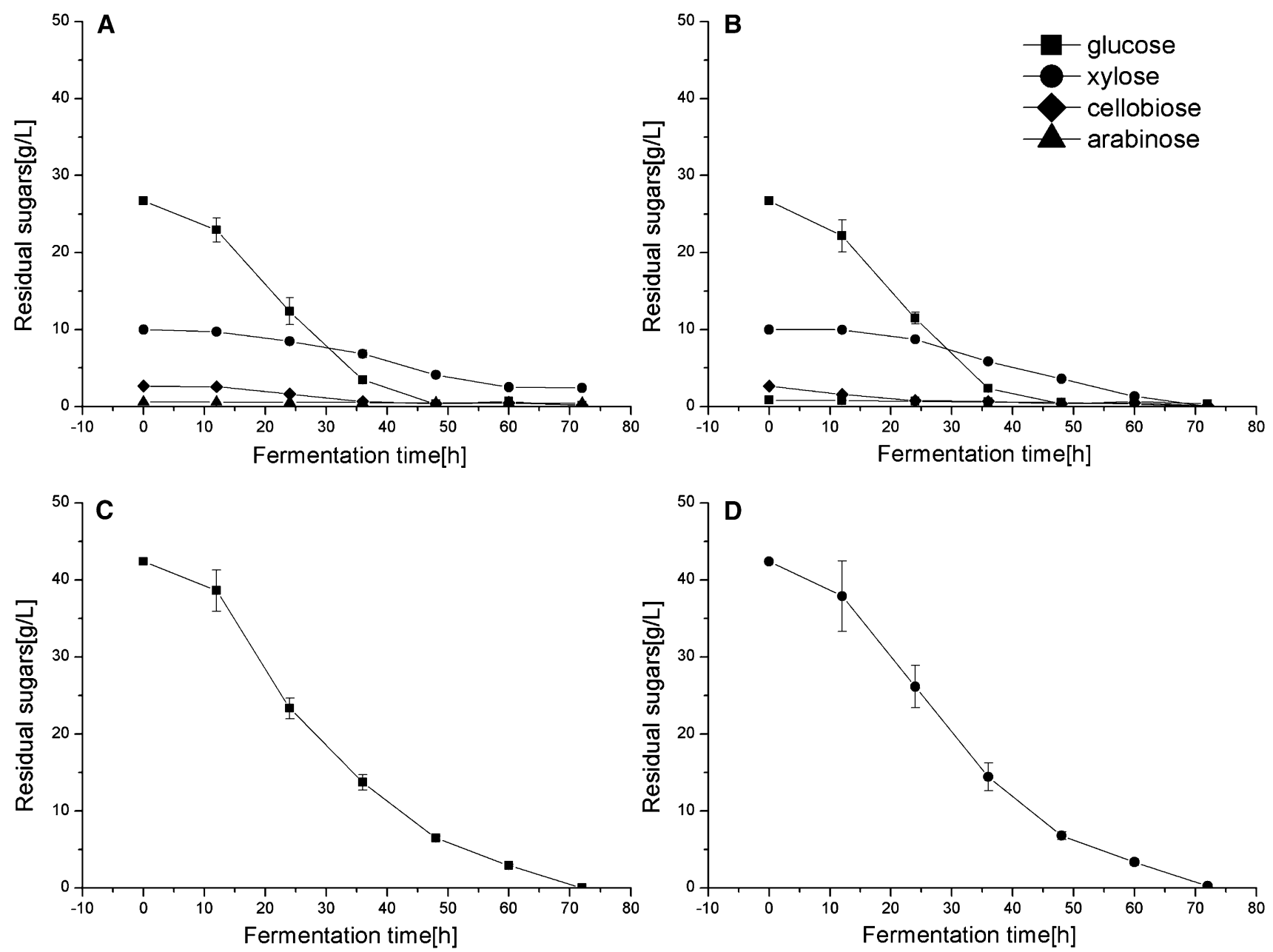

Fig. 5 Sugar utilization in different mediums. a Hydrolyzate, $\mathbf{b}$ simulated hydrolyzate medium, $\mathbf{c}$ glucose medium, $\mathbf{d}$ xylose medium

concentrations as functions of fermentation time in the four different mediums are shown in Fig. 6. As can be seen, after $72 \mathrm{~h}$ fermentation, butanol concentrations of 7.1, 7.0, 7.0 and $7.7 \mathrm{~g} / \mathrm{L}$ can be achieved in hydrolyzate, simulated hydrolyzate medium, glucose medium and xylose medium, respectively, and the corresponding total ABE concentration were $11.2,11.1,11.5$ and $12.4 \mathrm{~g} / \mathrm{L}$, respectively (Fig. 7). The ABE yield from total sugar utilized in all medium ranged from 0.26 to $0.28 \mathrm{~g} / \mathrm{g}$ sugar, as shown in Fig. 8. However, when SLC was as low as $0.74 \mathrm{~g} / \mathrm{L}$, the sugar utilization was $92.7 \%$ which was still inhibited, compared to the simulated hydrolyzate $(98.8 \%)$ and glucose medium $(100 \%)$. But the yield of ABE $(0.286 \mathrm{~g} / \mathrm{g}$ sugar) was higher than the simulated hydrolyzate $(0.264 \mathrm{~g} /$ $\mathrm{g}$ sugar) and glucose medium $(0.273 \mathrm{~g} / \mathrm{g}$ sugar $)$. Wang et al. [2] reported that there was an improvement on ABE yield when the SLC is between 0.44 and $3.32 \mathrm{~g} / \mathrm{L}$ while the utilization of sugar was inhibited when SLC exceeded $1.77 \mathrm{~g} / \mathrm{L}$. Thus, the concentration of ABE was higher than the control medium when the SLC was between 0.44 and 

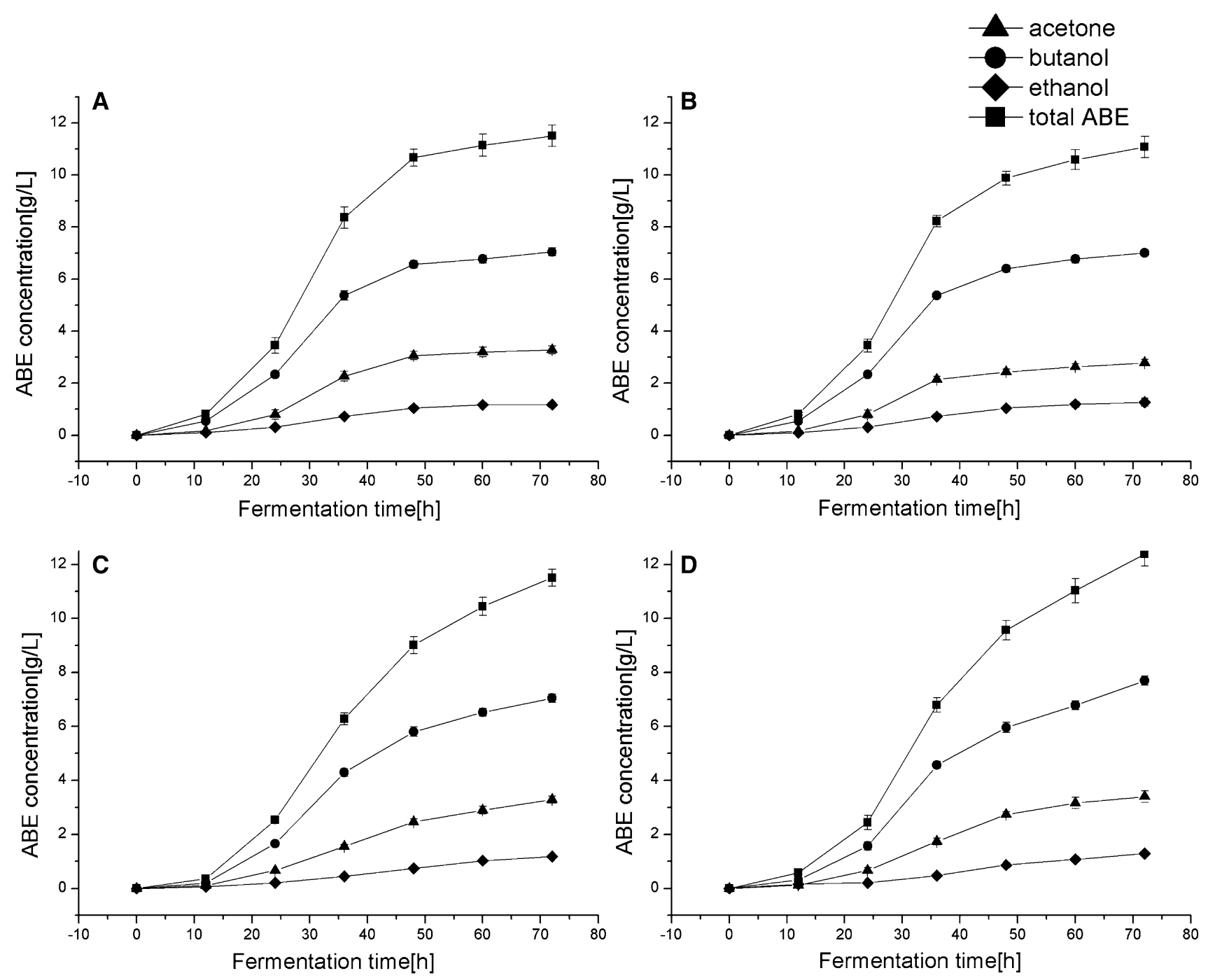

Fig. 6 ABE fermentation of different mediums. a Hydrolyzate, b simulated hydrolyzate medium, $\mathbf{c}$ glucose medium, d xylose medium

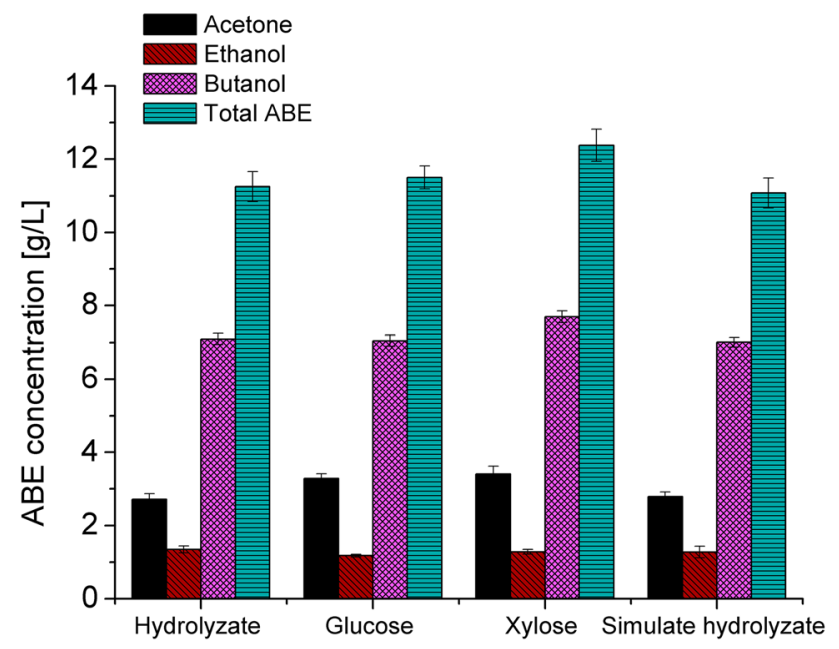

Fig. 7 The final ABE concentration in different mediums

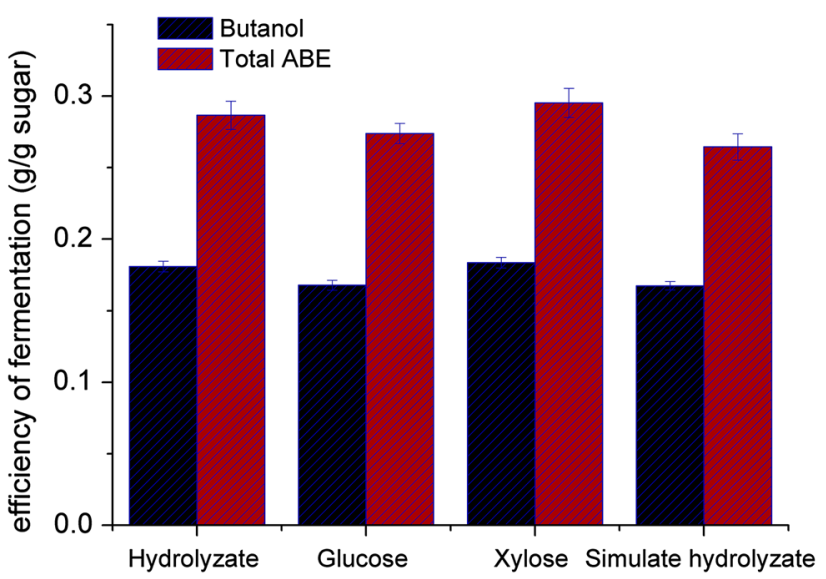

Fig. 8 Efficiency of fermentation in different mediums 
$0.89 \%$. In our case, although the concentration of $\mathrm{ABE}$ was similar, the sugar utilization and $\mathrm{ABE}$ yield of hydrolyzate had an obviously difference from the control medium. The ABE yield was improved like the Ref. [2], but the utilization was inhibited when the SLC was as low as $0.74 \mathrm{~g} / \mathrm{L}$. The different behavior is possibly due to the different composition/structure of SLC derived from different pretreatment methods. Reference [2] used alkaline peroxide pretreatment which could make the phenolic groups of the lignin decomposed, and hence the SLC generated during enzyme hydrolysis could have less phenolic groups compared to the ATSE pretreatment. More phenolic groups in SLC may lead to the different behavior of fermentation samples, but more specific studies (e.g., quantitative analysis of the composition of SLC) are needed in future. All in all, $0.112 \mathrm{~g} / \mathrm{g}$ raw corn stover (o.d.) of $\mathrm{ABE}$ yield can be achieved, indicating that hydrolyzate obtained from enzymatic hydrolysis of ATSE pretreated corn stover after washing could be a good substrate for $\mathrm{ABE}$ production.

\section{Conclusion}

A high sugar recovery was obtained at high solid loading (6\%) enzymatic hydrolysis using the ATSE pretreated corn stover after washing. The enzymatic hydrolyzate with low SLC concentration of $0.74 \mathrm{~g} / \mathrm{L}$ obtained from the enzymatic hydrolysis was chosen for ABE fermentation test. The reducing sugar concentration of $42.4 \mathrm{~g} / \mathrm{L}$ and sugar recovery of $83.8 \%$ were achieved after hydrolysis. In addition, without any additional detoxification process, about $70 \%$ of the fermentable sugar in the corn stover was utilized by the microbe, the hydrolyzate had similar fermentation performance to the controlled glucose and simulated hydrolyzate medium in $\mathrm{ABE}$ concentration, and the yield of $\mathrm{ABE}$ was $0.112 \mathrm{~g} / \mathrm{g}$ raw corn stover.

Acknowledgments We are grateful for the support of the Natural Science Foundation of China and Shandong Province (No. 21206814, No. 21201174 and BS2009ZZ001), the SHELL Research Foundation as well as the National High Technology Research and Development Program ("863" program) of China (No. 2012AA022301).

\section{References}

1. Wang X, Feng H, Li ZY (2012) Ethanol production from corn stover pretreated by electrolyzed water and a two-step pretreatment method. Chin Sci Bull 57(15):1796-1802

2. Wang L, Chen H (2011) Increased fermentability of enzymatically hydrolyzed steam-exploded corn stover for butanol production by removal of fermentation inhibitors. Process Biochem 46(2):604-607

3. Qureshi N, Sahaa BC, Hector RE, Hughes SR, Cotta MA (2008) Butanol production from wheat straw by simultaneous saccharification and fermentation using Clostridium beijerinckii: Part I-Batch fermentation. Biomass Bioenerg 32(2):168-175

4. Wang ZJ, Zhu JY, Zalesny RS Jr, Chen KF (2012) Ethanol production from poplar wood through enzymatic saccharification and fermentation by dilute acid and SPORL pretreatments. Fuel 95(1):606-614

5. Alvira P, Tomas-Pejo E, Ballesteros M, Negro MJ (2010) Pretreatment technologies for an efficient bioethanol production process based on enzymatic hydrolysis: a review. Bioresour Technol 101(13):4851-4861

6. Lee SH, Teramoto Y, Endo T (2010) Enhancement of enzymatic accessibility by fibrillation of woody biomass using batch-type kneader with twin-screw elements. Bioresour Technol 101(2): 769-774

7. Kadam KL, Chin CY, Brown LW (2009) Continuous biomass fractionation process for producing ethanol and low-molecularweight lignin. Environ Prog Sustain 28(1):89-99

8. Karunanithy C, Muthukumarappan K (2010) Influence of extruder temperature and screw speed on pretreatment of corn stover while varying enzymes and their ratios. Appl Biochem Biotechnol 162(1):264-279

9. Zhang SJ, Xu YX, Hanna MA (2012) Pretreatment of corn stover with twin-screw extrusion followed by enzymatic saccharification. Appl Biochem Biotech 166(2):458-469

10. Wang HS et al. Process for the pretreatment of cellulose biomass. Chinese patent application number 201210424816.8

11. Liu C, van der Heide E, Wang HS, Li B, Yu G, Mu XD (2013) Alkaline twin-screw extrusion pretreatment for fermentable sugar production. Biotechnol Biofuels 2013(6):97. doi:10.1186/17546834-6-97

12. Ezeji T, Qureshi N, Blaschek HP (2007) Butanol production from agricultural residues: impact of degradation products on Clostridium beijerinckii growth and butanol fermentation. Biotechnol Bioeng 97(6):1460-1469

13. Palmqvist E, Hahn-Hagerdal B (2000) Fermentation of lignocellulosic hydrolysates. I: inhibition and detoxification. Bioresour Technol 74(1):17-24

14. Qureshi N, Saha BC, Hector RE, Dien B, Hughes S, Liu S, Iten L, Bowman MJ, Sarath G, Cotta MA (2009) Production of butanol (a biofuel) from agricultural residues: Part II-Use of corn stover and switchgrass hydrolysates. Biomass Bioenerg 34(4):566-571

15. Cho DH, Lee YJ, Um Y, Sang BI, Kim YH (2009) Detoxification of model phenolic compounds in lignocellulosic hydrolysates with peroxidase for butanol production from Clostridium beijerinckii. Appl Microbiol Biotechnol 83(6):1035-1043

16. Mu XD, Sun W, Liu C, Wang HS (2011) Improved efficiency of separate hexose and pentose fermentation from steam-exploded corn stalk for butanol production using Clostridium beijerinckii. Biotechnol Lett 33(8):1587-1591

17. Li Q, Gao Y, Wang HS, Li B, Liu C, Yu G, Mu XD (2012) Comparison of different alkali-based pretreatments of corn stover for improving enzymatic saccharification. Bioresour Technol 125:193-199

18. Qureshi N, Blaschek HP (1999) Butanol recovery from model solution/fermentation broth by pervaporation: evaluation of membrane performance. Biomass Bioenerg 17(2):175-184

19. Sluiter A, Hames B, Ruiz R, Scarlata C, Sluiter J, Templeton D, Crocker D (2008) Determination of structure carbohydrates and lignin in biomass. Laboratory Analytical Procedure (LAP). Determination of structure carbohydrates and lignin in biomass. Laboratory Analytical Procedure (LAP). NREL/TP-510-42618. National Renewable Energy Laboratory, Golden, Colorado, USA

20. Mussatto SI, Roberto IC (2006) Chemical characterization and liberation of pentose sugars from Brewer's spent grain. J Chem Technol Biotechnol 81(3):268-274 
21. Zhu JY, Gleisner R, Scott C, Luo XL, Tian S (2011) High titer ethanol production from simultaneous enzymatic saccharification and fermentation of aspen at high solids: a comparison between SPORL and dilute acid pretreatments. Bioresour Technol 102(19):8921-8929

22. Alvira P, Moreno AD, Ibarra D, Saez F, Ballesteros M (2013) Improving the fermentation performance of saccharomyces cerevisiae by laccase during ethanol production from steamexploded wheat straw at high-substrate loadings. Biotechnol Prog 29(1):74-82
23. Ezeji T, Blaschek HP (2008) Fermentation of dried distillers' grains and solubles (DDGS) hydrolysates to solvents and valueadded products by solventogenic clostridia. Bioresour Technol 99(12):5232-5242

24. Huesemann MH, Kuo LJ, Urquhart L, Gill GA, Roesijadi G (2012) Acetone-butanol fermentation of marine macroalgae. Bioresour Technol 108:305-309

25. Mou HY, Orblin E, Kruus K, Fardim P (2013) Topochemical pretreatment of wood biomass to enhance enzymatic hydrolysis of polysaccharides to sugars. Bioresour Technol 142:540-545 